\title{
Glycogen metabolism and glycogen storage disorders
}

\author{
Shibani Kanungo ${ }^{1}$, Kimberly Wells ${ }^{1}$, Taylor Tribett $^{1}$, Areeg El-Gharbawy ${ }^{2}$ \\ ${ }^{1}$ Department of Pediatric and Adolescent Medicine, Western Michigan University Homer Stryker MD School of Medicine, Kalamazoo, MI, USA; \\ ${ }^{2}$ Department of Pediatrics, University of Pittsburgh Medical Center, Pittsburgh, PA, USA \\ Contributions: (I) Conception and design: S Kanungo; (II) Administrative support: S Kanungo; (III) Provision of study materials or patients: S \\ Kanungo; (IV) Collection and assembly of data: All authors; (V) Data analysis and interpretation: S Kanungo; (VI) Manuscript writing: All authors; \\ (VII) Final approval of manuscript: All authors. \\ Correspondence to: Shibani Kanungo, MD, MPH. Department of Pediatric and Adolescent Medicine, Western Michigan University Homer Stryker \\ MD School of Medicine, 1000 Oakland Drive, Kalamazoo MI 49008, USA. Email: Shibani.Kanungo@med.wmich.edu.
}

\begin{abstract}
Glucose is the main energy fuel for the human brain. Maintenance of glucose homeostasis is therefore, crucial to meet cellular energy demands in both - normal physiological states and during stress or increased demands. Glucose is stored as glycogen primarily in the liver and skeletal muscle with a small amount stored in the brain. Liver glycogen primarily maintains blood glucose levels, while skeletal muscle glycogen is utilized during high-intensity exertion, and brain glycogen is an emergency cerebral energy source. Glycogen and glucose transform into one another through glycogen synthesis and degradation pathways. Thus, enzymatic defects along these pathways are associated with altered glucose metabolism and breakdown leading to hypoglycemia \pm hepatomegaly and or liver disease in hepatic forms of glycogen storage disorder (GSD) and skeletal \pm cardiac myopathy, depending on the site of the enzyme defects. Overall, defects in glycogen metabolism mainly present as GSDs and are a heterogenous group of inborn errors of carbohydrate metabolism. In this article we review the genetics, epidemiology, clinical and metabolic findings of various types of GSD, and glycolysis defects emphasizing current treatment and implications for future directions.
\end{abstract}

Keywords: Glycogen; glycogen storage disorder (GSD); hepatomegaly; hypoglycemia; rhabdomyolysis

Submitted Oct 16, 2018. Accepted for publication Oct 23, 2018.

doi: 10.21037/atm.2018.10.59

View this article at: http://dx.doi.org/10.21037/atm.2018.10.59

\section{Introduction}

Glycogen is a branched polymer of glucose stored predominantly in the liver and muscle during times of plenty only to be broken down and released as glucose during times of need. It appears as a densely branched snowflake in 3-D with Glycogen in, a glycosyltransferase enzyme in the center. Glycogen in, initiates the formation of glycogen by attaching glucose residues from UDP glucose and subsequent linear prolongation up to ten glucose molecules making the core unit. To this core unit, subsequent attachment of glucose occurs by enzymes such as glycogen synthase, which adds the alpha 1,4 linkages, and glycogen debranching enzyme, which adds the alpha 1,6 branch points every $12-13$ glucose residues to elongate and form a globular granule of 30,000 glucose units $(1,2)$. The degradation of glycogen into usable glucose molecules result from combined actions of glycogen phosphorylase, glycogen debranching enzyme, and phosphoglucomutase.

Glucose is stored as glycogen primarily in the cytoplasm of liver and muscle cellular tissue, and in small amounts in brain tissues. While glycogen in the liver acts as the main depot source that maintains blood glucose homeostasis, glycogen in skeletal muscles provides energy to muscles during high-intensity exertion.

Liver glycogen breaks down to maintain blood glucose concentrations on demand. Alternatively, post prandial excess blood glucose triggers insulin release, and glycogen synthesis and storage in the liver and muscles. During stress or short periods of fasting, glucagon signals the liver to 
break down glycogen stores into glucose (glycogenolysis). Glucose is then released into the circulation maintaining blood glucose homeostasis during the times of high energy demands or fasting.

Skeletal muscles use glycogen in a similar manner, however, typically after several minutes of strenuous activity to keep up with its energy requirements.

Glucose and glycogen convert into one another via synthesis or degradation through various steps in the glycogen metabolism pathways as presented schematically in Figure 1.

Mutations in genes encoding individual enzymes in the glycogen metabolism pathway lead to a class of diseases named glycogen storage disorders (GSDs), whereas defects in glucose oxidation are identified as glycolysis defects. Depending on the enzyme defect and its relative expression in the liver, kidney, skeletal muscle, or heart, the clinical manifestations of GSDs varies from one disorder to the other. As a general rule, Liver GSDs commonly present with fasting hypoglycemia \pm hepatomegaly. While muscle GSDs present in one of two different ways: exercise intolerance and rhabdomyolysis or fixed muscle weakness without rhabdomyolysis (3). Often exercise intolerance and rhabdomyolysis is seen in dynamic disorders like McArdle (GSD5), and Tarui (GSD7) diseases, while fixed muscle weakness without rhabdomyolysis is seen in cytoplasmic disorders associated with glycogenolysis defects as debrancher defect (GSD3a) or lysosomal glycogen breakdown defects as Pompe disease (GSD2) (4). Genetic defects with clinical features and epidemiology of each disorder of the glycogen metabolism pathway are summarized in Table 1. We will review glycogenosis and GSDs involving the liver, muscle, brain and include the lysosomal storage of glycogen-Pompe disease.

\section{Liver glycogenosis and GSDs}

\section{GSD type 0a (GSDOa)}

\section{Clinical}

GSD0a, is liver glycogen synthase enzyme deficiency with impaired ability to incorporate UDP-glucose onto glycogen strands and elongate it within the liver. This leads a lack of hepatic glycogen storage, absence of hepatomegaly and lack of liver's ability to maintain glucose homeostasis during fasting leading to hallmark presentation of ketotic hypoglycemia after an overnight fast in the absence of hepatomegaly and hypoglycemic seizures (5-7).
Another consequence of glycogen synthase deficiency is excess of substrates of the glycolytic pathway due to a reduced flow into glycogenosis (see Figure 1). The net effect results in transient post- prandial hyperglycemia and hyperlactatemia $(5,8)$. However, some affected individuals may be asymptomatic or go undiagnosed $(6,9)$.

\section{Metabolic findings and diagnosis}

GSD0a main clinical presentations include fasting Ketotic hypoglycemia without hepatomegaly, supported by a low pre-prandial blood glucose level associated with high blood and urine ketones and a high post-prandial blood glucose, lactate and alanine levels. Ultimately diagnosis can be confirmed by non-invasive DNA analysis of the GYS2 gene or invasive enzymatic analysis from liver biopsy (10).

\section{Treatment}

Current treatment for GSD0a includes avoiding fasting, and frequent meals that are high in protein, to promote gluconeogenesis and uncooked cornstarch (UCCS) as needed in the day and or at nighttime to prevent hypoglycemia $(8,11)$. With proper management, GSD0a has good prognosis.

\section{Genetics and epidemiology}

GSD0a is an autosomal recessive disorder caused by a mutation in the GYS2 gene located at $12 \mathrm{p} 12.2$ that codes for the hepatic isoform of glycogen synthase (12). There are less than 30 reported cases of GSD0a (13).

\section{GSD type 1 (GSD1)}

GSD1 is caused by defective glycogenolysis and gluconeogenesis and is subdivided into two types: GSD1a and GSD1b.

\section{GSD1a}

Clinical

GSD1a, also known as Von Gierke disease or Glucose6-phosphatase (G6Pase) deficiency results from impaired ability of the hydrolase subunit of G6Pase, also known as G6Pase- $\alpha$ to hydrolyze G6P, leading to impaired function of G6Pase in removing the phosphate group from glucose-6phosphate (G6P), thus, impairing free glucose availability in the last step of gluconeogenesis (see Figure 1); resulting in impaired glucose homeostasis and hypoglycemia. G6Pase- $\alpha$ is necessary to convert fructose and galactose into glucose and is expressed in the liver, kidney, and intestines. 


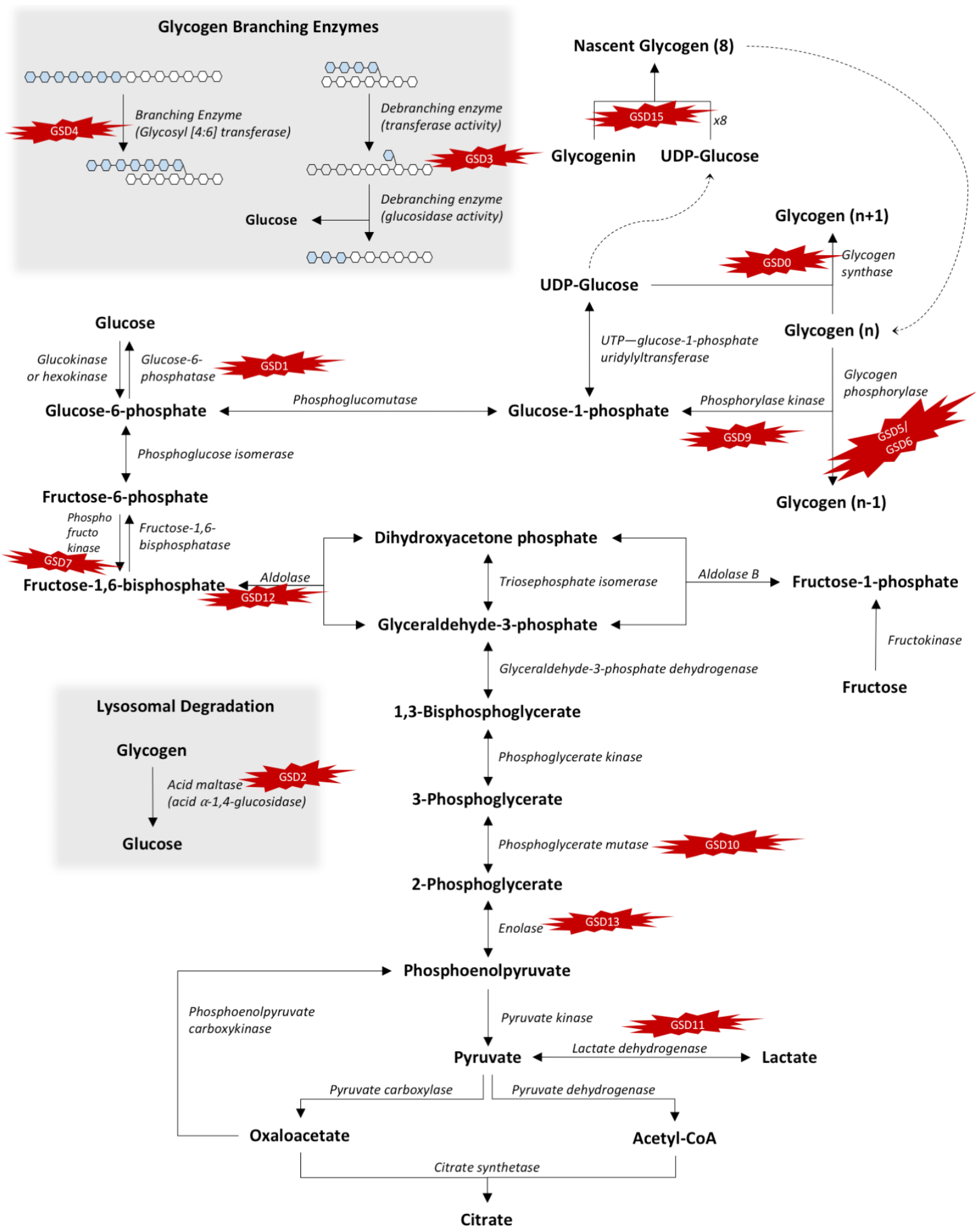

Figure 1 Glycogen metabolism pathway and defects. Enzyme affected are shown in italics and the correlating GSD are inserted in the starshapes. GSD, glycogen storage disorder. 


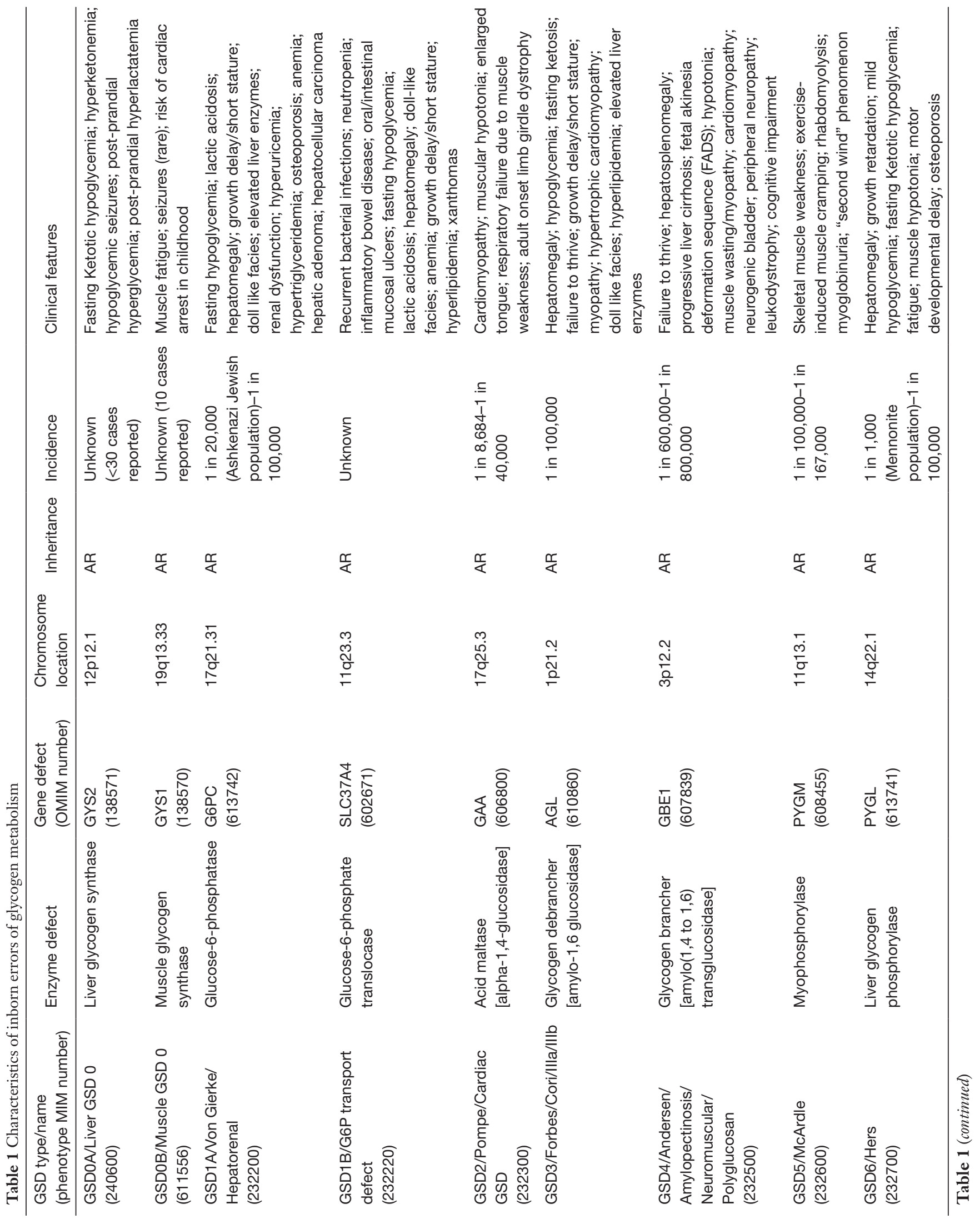




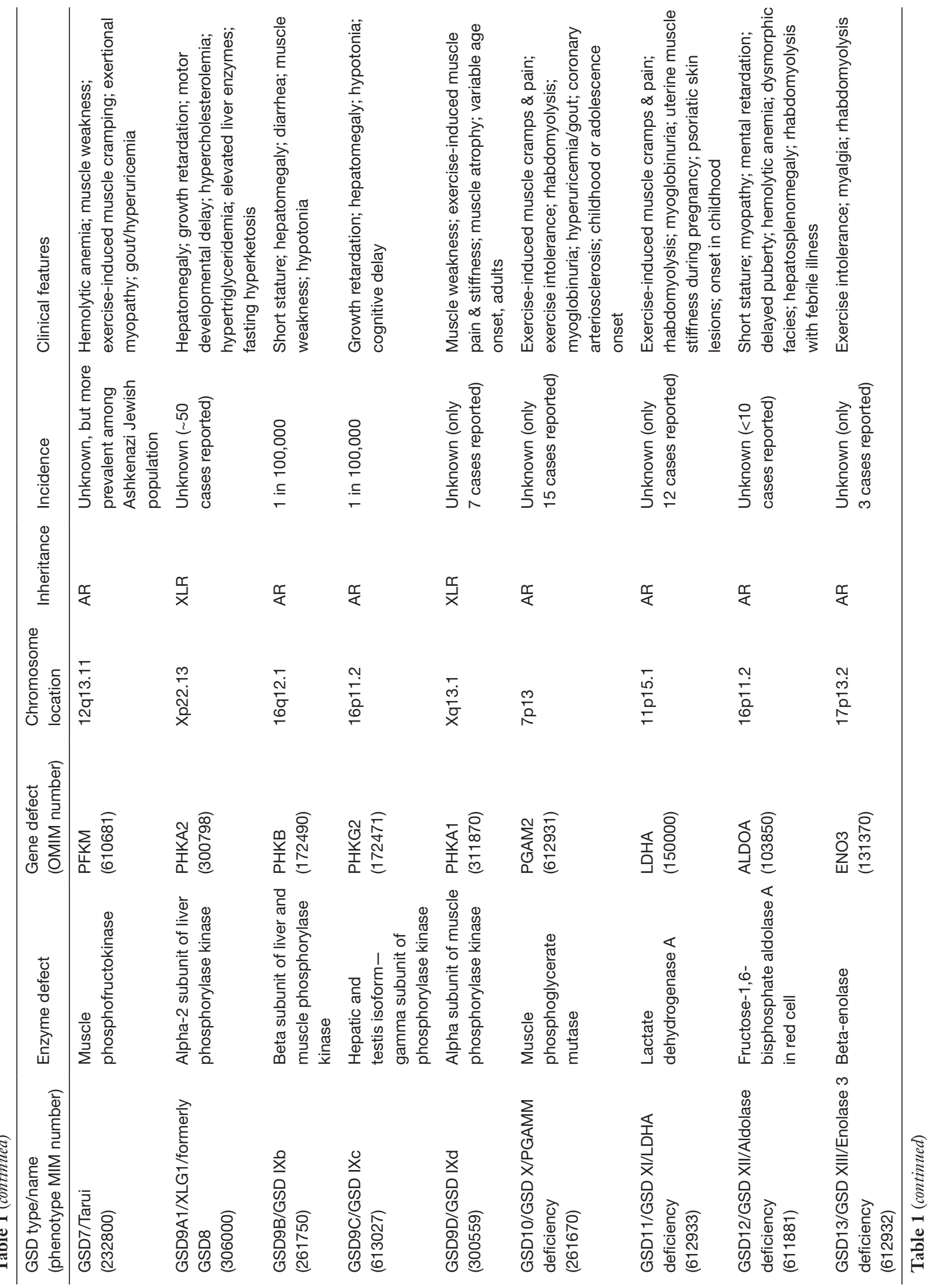




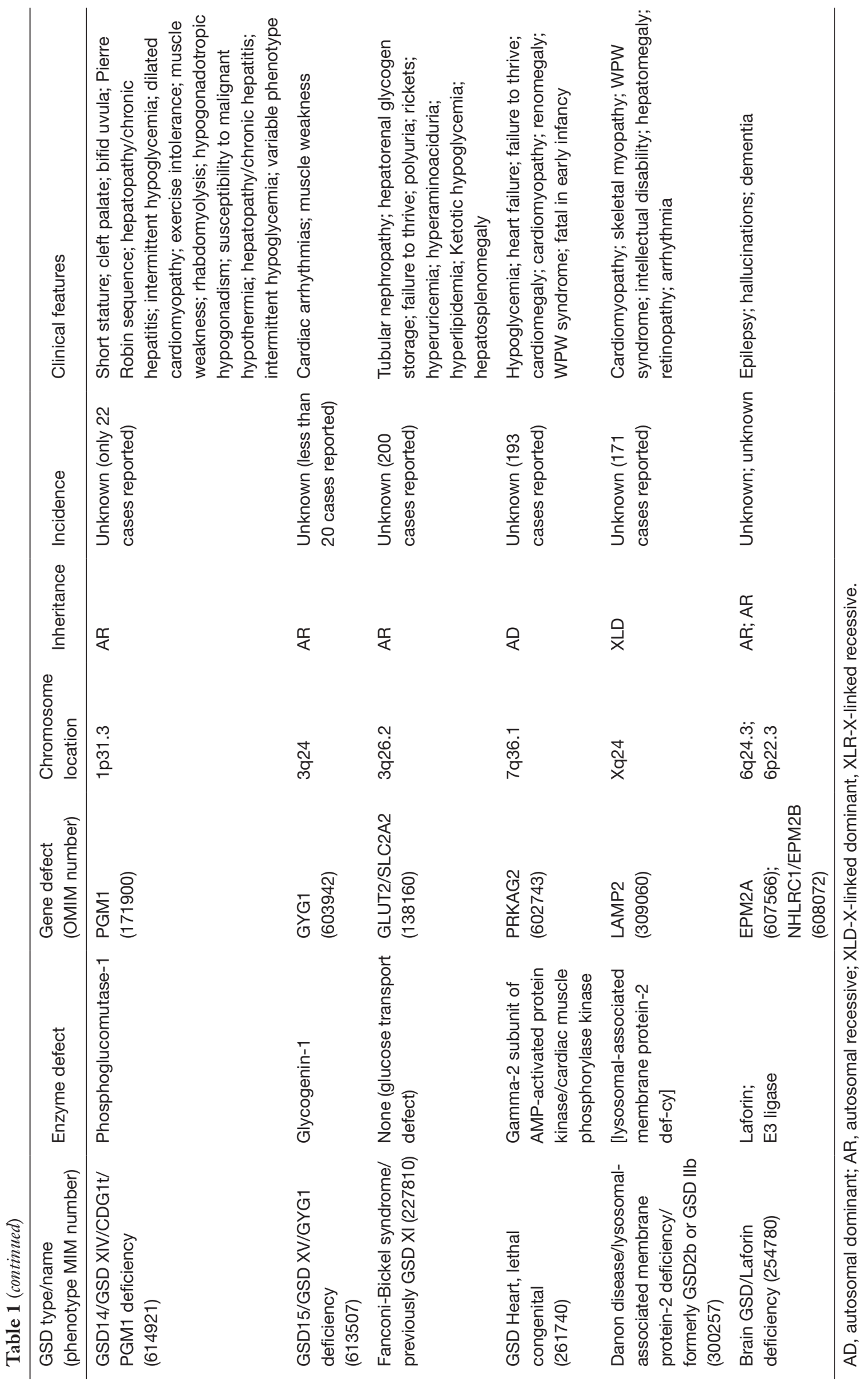


Patients typically present by 6 months of age with fasting hypoglycemia or hepatomegaly, and are found to have protuberant abdomen, stunted growth, and doll-like facies (14-16). Long term complication of from kidney glycogen accumulation include GSD nephropathy, chronic kidney disease, polycystic kidney and renal cancer, hyperuricemia associated with renal stones and renal tubular acidosis $(16,17)$. Poor disease management or disease progression can lead to short stature, osteoporosis, anemia, polycystic ovarian syndrome, and hepatic adenomas which may be associated with the risk of transforming into hepatocellular carcinoma (16-20).

\section{Metabolic findings and diagnosis}

Patients with GSD1a typically have hypoglycemia from impaired last step of gluconeogenesis as discussed above, hyperuricemia and hypertriglyceridemia from excess G6P resulting in increased flux through pentose phosphate pathway and lipogenesis respectively, lactic acidosis from excess G6P over working the glycolytic pathway (16). GSD1a patients with hyperlipidemia seem to have increased fraction of apolipoprotein E (apoE) with suggested protective effect against atherosclerosis (21).

Initial clinical presentation of fasting hypoglycemia, lactic acidosis, hyperuricemia and hypertriglyceridemia can be confirmed by enzyme activity assay and or mutation analysis of both G6PC and SLC37A4 simultaneously due to the overlap of presentations seen in GSD1a and GSD1b $(15,22)$.

Prenatal genetic diagnosis on chorionic villus sampling was reported in a family with known familial mutation (23).

\section{Treatment}

The main aim of treatment in GSD1a is to maintain normoglycemia or avoid hypoglycemia. ACMGG Consensus guidelines can be reviewed for further details on current guidelines on diagnosis and management of GSD1 (20). Nutritional approaches with frequent feedings of formula, meals, snacks, and UCCS including use of nasogastric and gastrostomy tubes are the cornerstone to maintain glucose homeostasis throughout the day and night (11). Glycosade, a modified form of cornstarch helps maintain normoglycemia overnight for a longer time in older children (24). Simple sugars as fructose, sucrose and galactose are restricted because of their contribution to lactic acidosis (11). A high-protein diet has been related to kidney damage and cannot be effectively converted into glucose because of the limited G6Pase activity (11). Hyperuricemia can improve with metabolic control or allopurinol (15). Hyperlipidemia may improve with metabolic control, but has historically been treated with fibrates, statins, niacin, fish oil, and medium-chain triglyceride milk (11).

Liver transplantation has been associated with favorable outcomes in severe disease (25). Liver transplantation corrects glucose homeostasis, but does not prevent renal dysfunction $(16,25)$. However, based on the calculated liver disease score, GSD1a patients are typically low for liver transplant priority (26). Multiple studies using animal models have showed the efficiency of gene therapy in correcting glucose homeostasis and improved metabolic profiles (22). A clinical phase I/II trial (NCT03517085) using adeno-associated virus 8 (AAV8) to deliver G6Pase- $\alpha$ gene to the liver. in an attempt to correct defective G6PC (27) may help establish gene therapy as a promising future approach.

\section{Genetics and epidemiology}

GSD1a mode of inheritance is autosomal recessive; with mutations in the $G 6 P C$ gene on chromosome 17 p21.31 encoding $\alpha$-glucose-6-phosphatase (G6Pase- $\alpha$ ) enzyme (28). GSD1 incidence is about 1 in 100,000 with GSD1a accounting for $80 \%$ of diagnosis $(16,22)$. Within the Ashkenazi Jewish population, the suggested incidence of GSD1a is 1 in 20,000 (29). No clear-cut genotypephenotype correlation has been identified (20).

\section{GSD1b}

\section{Clinical}

GSD1b shares the same clinical presentation of GSD1a with, additional hallmark features: neutropenia and impaired neutrophil function; an inflammatory bowel disease (IBD) with a presentation similar to Crohn's disease, thyroid autoimmunity and hypothyroidism (30-32).

\section{Metabolic findings and diagnosis}

The G6PT enzyme is a transmembrane protein found within the endoplasmic reticulum and functions to move G6P into the endoplasmic reticulum. G6Pase- $\alpha$ and G6PT together as the G6Pase complex maintains glucose homeostasis. G6PT is ubiquitously expressed with G6Pase complexes throughout the body, while G6Pase- $\alpha$ is localized to the liver, kidney, and intestines, leads myeloid cell energy homeostasis disruption and the resulting neutropenia. Neutropenia can be severe, leading to recurrent infections and milder neutropenia with other features of GSD1b has been described with a homozygous mutation in G6PC gene (22,32).

Due to clinical presentation overlap seen in GSD1a and GSD1b, both G6PC and SLC37A4 should be analyzed 
for mutations simultaneously in patients with suspected GSD1 (22).

\section{Treatment}

In addition to GSD1a treatment approaches, the only difference in GSD1b includes, addressing neutropenia and IBD with granulocyte colony-stimulating (G-CSF) to decreases the number and severity of infections and inflammation (31). Liver transplantation in GSD1b will correct glucose homeostasis, but effects on neutropenia and bowel disease are variable and less clear (25).

\section{Genetics and epidemiology}

GSD1b has autosomal recessive inheritance, with 92 different reported with 31 confirmed as pathogenic mutations in SLC37A4 gene on chromosome 11q23 (33), encoding glucose-6-phosphate translocase (G6PT) enzyme (GDE); and no apparent genotype-phenotype relationship $(15,22)$.

\section{GSD type 6 (GSD6)}

\section{Clinical}

GSD6, also known as Hers disease or liver phosphorylase enzyme deficiency, is a glycogenolysis defect with impaired interconversion of unphosphorylated form into active phosphorylated form of liver phosphorylase enzyme, necessary to remove the terminal branch glycosyl unit of glycogen to form glucose 1 phosphate (34). Varied clinical spectrum include mild to severe presentation of hepatomegaly, Ketotic hypoglycemia, with excessive glycogen accrual seen in liver biopsy (10). Though, considered a milder disease, long term complications are not well studied (35).

\section{Metabolic findings and diagnosis}

Ketotic hypoglycemia +/- hepatomegaly +/- growth delay presentation can be varied-Diagnostic confirmation includes molecular analysis of PYGL gene, liver biopsy measuring liver phosphorylase enzyme activity (36).

\section{Treatment}

Mainly is symptomatic, with frequent intake of complex carbohydrate, and high protein diet and avoiding fasting $(10,11)$.

\section{Genetics and epidemiology}

GSD6 is an autosomal recessive disorder, with very few documented cases, and with mutation in PYGL gene on chromosome 14q22.1 (10,36,37).

\section{GSD9A1 \& GSD9A2}

\section{Clinical}

GSD9A1 \& GSD9A2 result from impaired phosphorylase kinase activity in the liver or erythrocyte (GSD9a1) or only liver (GSD9a2). They are reported more in males, and considered most common of all GSD9. Though, initially thought to be mild disease (38); severe presentations of liver cirrhosis are also reported. Common early childhood presentations include hepatomegaly, growth \& motor developmental delay, hypercholesterolemia, hypertriglyceridemia, elevated liver enzymes, and fasting hyperketosis, which resolve with puberty (39).

\section{Metabolic findings and diagnosis}

Clinical suspicion in males with hepatomegaly and fasting hyperketosis, hyperlipidemia, elevated liver enzymes, and normal lactate \& uric acid levels; should be confirmed with PHKA2 gene molecular analysis and or erythrocyte phosphorylase kinase activity (39).

\section{Treatment}

Symptomatic to prevent hypoglycemia with frequent meals and snacks, high protein diet, and complex carbohydrates.

\section{Genetics and epidemiology}

GSD9a has X-linked inheritance with mutations in the PHKA2 gene on chromosome Xp22.13 that encodes liver phosphorylase kinase (40).

\section{GSD9c}

\section{Clinical}

GSD9c results from impaired gamma unit of phosphorylase kinase enzyme function in liver and testis, with early childhood presentations of recurrent hypoglycemia, hepatomegaly progressing to liver cirrhosis and end stage liver disease; apart from motor delay, hepatosplenomegaly, renal tubular damage and muscle weakness (35). Because the gamma subunit contains the catalytic site of the enzyme, GSD9C typically has a more severe phenotype. In personal experience (SK unpublished data), a teenager presented with seizure disorder, microcephaly, intellectual disability, short stature apart from clinical presentations noted above.

\section{Metabolic findings and diagnosis}

Apart from clinical presentation noted above, elevated liver enzymes and lactate with severe fasting ketosis in setting of 
normal triglycerides creatine kinase (CK) and uric acid can be seen. Measurement of enzyme activity in liver may help but diagnostic confirmation includes molecular analysis of PHKG2 gene (41).

\section{Treatment}

Nutritional approaches to prevent recurrent hypoglycemia with high-protein and complex carbohydrates and symptomatic treatment and management for any hypoglycemia related complications may be helpful. In personal experience (SK unpublished data), teenage presentation of a GSD9c case with liver failure was treated successfully with liver transplantation and at 3-year post transplantation, showed improvement in cognitive abilities in late adolescence, to secure successful vocational training and employment, improved muscle strength, resolution of hepatosplenomegaly and seizures.

\section{Genetics and epidemiology}

GSD9C is an autosomal recessive disorder caused by mutations of the PHKG2 gene which encodes the gamma subunit of phosphorylase kinase on chromosome 16p11.2 (42).

\section{Liver \& muscle glycogenosis and GSDs}

\section{GSD type 3}

Clinical

GSD3, also known as Cori Disease or Forbes disease results from glycogen debrancher enzyme (GDE) deficiency with impaired glycogen breakdown and abnormal glycogen accumulation, affecting liver, skeletal and cardiac muscles $(35,43)$. Clinical presentation in infancy is similar to GSD1 with hepatomegaly, fasting hypoglycemia, hyperlipidemia, growth delay/failure to thrive (44). However, significant liver enzyme elevations and lack of lactic acidosis in setting of fasting ketosis, CK elevation differentiates GSD3 in younger age; with absence of nephromegaly, presence of splenomegaly, improvement of liver size and function in adolescence; prior to progression to cirrhosis/liver failure later in life. Muscular symptoms become apparent during and after adolescence though hypertrophic cardiomyopathy seen in younger childhood $(43,44)$.

\section{Metabolic findings and diagnosis}

As noted above, characteristic findings include fasting hypoglycemia with ketosis, hyperlipidemia, elevated
CK, an inverse relationship between a patients age and liver enzymes, lack of lactic acidosis and hyperuricemia (35,43-45). A diagnosis can be made by mutation analysis of the $A G L$ gene (46) or liver biopsy to detect the enzymatic defect.

\section{Treatment}

Best approaches are nutritional with frequent meals, with high protein content and lesser amounts of UCCS (than in GSD1), or bedtime glycosade helps growth during adolescence (43). Though there are suggestions that a modified Atkins diet improves myopathy symptoms (47).

\section{Genetics and epidemiology}

GSD3 has autosomal recessive inheritance, with 58 different reported mutations in the $A G L$ gene on chromosome $1 \mathrm{p} 21.2$, encoding GDE; and an incidence of 1 in 100,000 (44).

\section{GSD 4}

\section{Clinical}

GSD4, also known as Andersen disease or Brancher deficiency, is a glycogenolysis defect with impaired and few $\alpha-1,6$-glycosidic bonds along glycogen chain, resulting in abnormal glycogen with limited branch points (limited dextran) similar to amylopectin or polyglucosan (10). Clinical presentation is variable and historically classified as two hepatic and four neuromuscular forms based upon age of onset and severity (48). More recent studies suggest that GSD4 phenotypes should be considered a continuum of disease as opposed to discreet subtypes $(49,50)$.

The classical hepatic GSD4 typically presents within 18 months of birth with patients having a failure to thrive, hepatosplenomegaly, and liver cirrhosis (51). As the disease progresses, liver failure ultimately results, leading to death by the age of 5 unless a liver transplant is performed (51). A non-progressive hepatic form with a similar presentation has also been described $(52,53)$.

Neuromuscular variants range in onset from in utero presenting perinatally as fetal akinesia deformation sequence (FADS) to adulthood as adult polyglucosan body disease (APBD) with wide severity range from perinatal death to mild symptoms (49). Commonly seen features of the neuromuscular variant of disease includes: hypotonia, muscle atrophy, myopathy, cardiomyopathy, central nervous system (CNS), and peripheral nerve system (PNS) dysfunction (10). 


\section{Metabolic findings and diagnosis}

Liver dysfunction with abnormal coagulation can be nonspecific findings and amylopectin like material deposition can be seen in liver, heart, muscle, brain, spinal cord or reduced glycogen branching enzyme (GBE) activity seen in liver, muscle or leukocyte; but confirmation made by molecular analysis of GBE1 gene (10).

\section{Treatment}

Unlike other liver GSDs, GSD4 has no specific treatment. Early liver transplant is indicated in patients with the classical hepatic form but only in absence of cardiac or CNS disease (10).

\section{Genetics and epidemiology}

GSD4 is rare and has autosomal recessive inheritance with mutations in the GBE1 gene on chromosome $3 \mathrm{p} 12.2$ encoding GBE.

\section{GSD9b}

\section{Clinical}

GSD9B, also known as phosphorylase kinase deficiency of liver and muscle, have predominant hepatomegaly, short stature seen in early childhood and, sometimes in addition, muscle weakness and hypotonia (39).

\section{Metabolic findings and diagnosis}

Can be asymptomatic, but hypoglycemia and reduced enzyme activity can be seen. Diagnosis is mainly confirmed by mutation analysis of the $P H K B$ gene.

\section{Treatment}

Symptomatic with prevention of hypoglycemia with hiprotein and complex carbohydrate diet; though there is no specific treatment for muscle disease (54).

\section{Genetics and epidemiology}

GSD9B is an autosomal recessive disorder caused by mutations of $\beta$ subunit of $P H K B$ gene on chromosome $16 \mathrm{q} 12.1$.

\section{Muscle glycogenosis and GSDs}

\section{GSDOb}

\section{Clinical}

GSD0b, also known as muscle glycogen synthase deficiency, is rare and seems to affect muscle mitochondrial structure and function apart from depleted glycogen (55). Known symptoms include muscle fatigue, exercise intolerance, recurrent exertional syncope, hypertrophic cardiomyopathy, sudden cardiac death without cardiomyopathy (55-57).

\section{Metabolic findings and diagnosis}

Clinical suspicion with molecular analysis of GYS1 gene provides diagnostic confirmation. Muscle biopsy can show depleted glycogen; oxidative fibers and abnormal mitochondria (55-57).

\section{Treatment}

No specific treatment, preventive measures, supportive therapy with high protein complex carbohydrates diet may help.

\section{Genetics and epidemiology}

GSD0b is an autosomal recessive disorder caused by mutations of GSY1 gene on chromosome 19q13.33 (55).

\section{GSD2}

\section{Clinical}

GSD2, also known as Pompe disease or acid maltase deficiency results from impaired lysosomal acid- $\alpha$ glucosidase (GAA) function and accumulation of lysosomal glycogen in skeletal, respiratory and cardiac muscle and often considered as lysosomal storage disorder (LSD) than GSD. It can present anytime from early infancy into adulthood, the most severe being the classic infantile-onset form, characterized by severe hypotonia, macroglossia, muscle and diaphragmatic weakness, hypertrophic cardiomyopathy with cardiomegaly +/- WolfParkinson White arrhythmias, and hepatomegaly with fatality from cardiac failure in untreated patients within the first year of life (58). A non-classical infantile form shows slower symptom progression, is less severe with no cardiomyopathy (59). Late-onset Pompe disease (childhood, juvenile, and adult forms) is often used to describe patients who present after the first year of life with muscle weakness, and hypotonia (60).

\section{Metabolic findings and diagnosis}

Clinical suspicion as noted above with characteristic evidence of hypertrophic cardiomyopathy with EKG findings of shortened PR interval and high QRS complexes and elevated CK is seen in the infantile-onset form. While, 
proximal myopathy with diaphragmatic weakness is seen in late-onset disease. Elevated blood aminotransferases and $\mathrm{CK}$ are common but diagnostic confirmation noted with deficient GAA enzyme activity in lymphocytes, fibroblasts, and muscle or molecular analysis of biallelic GAA gene (61). GAA activity is usually absent (in infantileonset disease) or decreased (in late-onset disease). Some genotype-phenotype correlations exist and determined by the type of the mutation $(62,63)$. Dried blood spot testing measuring GAA enzyme activity has helped GSD2 to be included in Newborn Screening (64). Evaluation of the CRIM status is important, since CRIM negative status is associated with poor response to ERT and poor prognosis, if immunomodulation is not started early (62).

Results of newborn screening in Taiwan demonstrated significant long-term benefits from the early identification and treatment of patients with infantile Pompe disease before symptoms appeared making an argument for its inclusion in newborn screening panels in many states in the U.S. and trialed in several countries $(65,66)$.

\section{Treatment}

Enzyme replacement therapy (ERT) using human recombinant acid $\alpha$-glucosidase, the only approved treatment in the US and Europe since 2006, is based on its ability to degrade accumulated lysosomal glycogen and improve cardiac and skeletal muscle function (35). Though, a negative cross reacting immune material (CRIM)-negative status has high anti-rhGAA IgG antibodies development and resultant reduced ERT therapeutic effect with poor outcomes if not treated early with immunosuppression $(65,67)$.

If early diagnosis of late-onset disease is made via newborn screening, the question of when to start treatment in an asymptomatic patient is debated. Improvement in pulmonary function is seen in symptomatic patients with late-onset disease (68).

\section{Genetics and epidemiology}

GSD2 is a pan-ethnic autosomal recessive disorder caused by mutations of the $G A A$ gene on chromosome $17 \mathrm{q} 25.3$. The increasing list of $G A A$ gene pathogenic mutations can be found at www.pompecenter.nl. The estimated prevalence is considered to be 1 in 5436 (35).

\section{GSD5}

Clinical

GSD5, also known as McArdle disease results from deficient muscle phosphorylase activity and results in impaired glycogenolysis leading to exercise intolerance, muscle weakness and cramping alleviated by rest, and exercise induced rhabdomyolysis. A common history of childhood onset exercise intolerance and a wide range of severity and age of onset reported with most serious complication being renal failure from myoglobinuria and rhabdomyolysis. A short low intensity warm up or 5-15 minutes interruption/ break, to rest or "second wind" often necessary to resume exercise (69).

\section{Metabolic findings and diagnosis}

Apart from clinical suspicion, elevated CK, myoglobinuria and renal dysfunction as common biochemical markers with additional non-invasive diagnostic confirmation with molecular analysis of PYGM gene is indicated. Invasive muscle biopsy with negative muscle phosphorylase activity can help diagnosis too.

\section{Treatment}

Oral sucrose loading 30-40 minutes before exercise helps exercise tolerance as exogenous fuel source to help energy gap with lack of endogenous glucose from glycogenolysis and free fatty acids availability until $\sim 10$ minutes into exercising (70).

Regular exercise of moderate intensity helps maximize circulatory capacity and increase fuel delivery to muscles (71).

\section{Genetics and epidemiology}

GSD5 is an autosomal recessive disorder caused by mutations of PYGM gene on chromosome 11q13.1.

\section{GSD7}

\section{Clinical}

GSD7, also known as Tarui disease results from deficient muscle subunit of phosphofructokinase (PFK) enzyme as a rate limiting factor, with resultant impaired glycogenolysis and glycolysis. The classical form is characterized by exercise intolerance, (often with rhabdomyolysis), muscle cramps and pain. In some cases jaundice accompanied by increased serum bilirubin, exercise related elevated CK levels, myoglobinuria and myogenic hyperuricemia may also be seen $(72,73)$. In addition, three other GSD7 subtypes are late-onset, infantile, and hemolytic. Lateonset GSD7 typically presents in later life with muscle cramps and myalgias although patients may show increased muscular weakness and fatigability in childhood. Patients 
with severe infantile form of GSD7 present with hypotonia early after birth and often die within their first year of life. Arthrogryposis and mental retardation may be present in cases who survived early death. The hemolytic form is characterized by non-spherocytic hemolytic anemia without muscle symptoms (72).

GSD7 though clinically similar to GSD5, is different with the absence of a second wind phenomenon and a detrimental, as opposed to beneficial, effect of glucose administration due to impaired fatty acid oxidation in GSD7 (73).

\section{Metabolic findings and diagnosis}

Presentations can include hyperbilirubinemia, increased reticulocytes due to the elevation of hemolysis from partial loss of PFK activity in erythrocytes, elevated CK, lactate dehydrogenase, and aspartate transaminase following acute exercise (4). Non-invasive diagnostic confirmation includes molecular analysis of PFKM gene (72).

Muscle biopsy or forearm exercise test showing elevated ammonia but reduced lactate can confirm impaired glycolysis following anaerobic exercise can be supportive.

\section{Treatment}

Symptomatic and preventive with avoiding strenuous exercise, high protein intake during exercise and avoiding exercise related simple sugars as sucrose intake.

\section{Genetics and epidemiology}

GSD7 is an autosomal recessive disorder caused by mutations of the PFKM gene on chromosome 12q13.11.

\section{GSD9D}

\section{Clinical}

GSD9D, also known as muscle phosphorylase kinase deficiency or $\mathrm{X}$-linked muscle glycogenosis results from impaired alpha subunit of the muscle phosphorylase kinase activity, associated with muscle weakness, atrophy, and exercise-induced pain and stiffness, with a variable age at onset, mainly seen in males, though can remain asymptomatic until intense exercise $(39,74)$.

\section{Metabolic findings and diagnosis}

CK may be elevated, but, diagnosis is confirmed by mutation analysis of the PHKA1 gene.

\section{Treatment}

Unknown but symptomatic hydration for muscle enzyme breakdown can help.

\section{Genetics and epidemiology}

GSD9D is an X-linked recessive disorder caused by mutations of the PHKA1 gene which encodes the alpha subunit of muscle phosphorylase kinase on chromosome $\mathrm{Xq} 13.1$.

The overall prevalence of GSD9 is estimated to be 1 in 100,000 (54).

\section{GSD10}

\section{Clinical}

GSD10 also known as PGAMM deficiency results from impaired muscle phosphoglycerate mutase-2 activity essential for conversion of 3-phosphoglycerate to 2-phosphoglycerate during glycolysis and resultant childhood or adolescence presentation of muscle cramping, rhabdomyolysis, and myoglobinuria precipitated by bursts of vigorous exercise (75).

\section{Metabolic findings and diagnosis}

Elevated CK, myoglobinuria can be confirmed noninvasively with molecular analysis of $P G A M$ gene (76). Enzymatic assay shows decreased muscle phosphoglycerate mutase-2 activity.

\section{Treatment}

Symptomatic myopathy management with hydration and avoidance of strenuous exercise.

\section{Genetics and epidemiology}

GSD10 is an autosomal recessive disorder caused by mutations of the PGAM2 gene on chromosome $7 \mathrm{p} 13$. Of the 15 cases reported in the medical literature, a founder exon1 null mutation noted in African Americans $(76,77)$.

\section{GSD11}

\section{Clinical}

GSD11 (78) also known as GSDXI results from impaired muscle $(M)$ isoform of lactate dehydrogenase enzyme essential for interconversion of lactate and pyruvate in muscle glycolysis with resultant fatigue, exertional myoglobinuria and also uterine pain and stiffness during pregnancy and labor (79).

\section{Metabolic findings and diagnosis}

Biochemical findings of elevated CK, lactate and 
myoglobinuria can be confirmed with molecular analysis of $L D H A$ gene. $\mathrm{LDH}$ activity in red blood cells is low or absent.

\section{Treatment}

No specific treatment. In pregnant women with GSD11 planned cesarean section can avoid increased risk of dystocia during labor (79).

\section{Genetics and epidemiology}

Lactate dehydrogenase A deficiency is an autosomal recessive disorder caused by mutations of the $L D H A$ gene on chromosome 11p15.1. The $\mathrm{H}$ isoform of $\mathrm{LDH}$ is found in the heart and encoded by the lactate dehydrogenase B gene on chromosome 12p12.1, but mutations found had no clinical significance (80).

Hepatorenal glycogenosis or Fanconi-Bickel Syndrome, listed as MIM\# 227810, previously also known as GSD $\mathrm{XI}$, is an autosomal recessive disorder with mutations in SLC2A2 gene encoding GLUT2 transporter, affecting glycogen accumulation in liver and kidney, proximal renal tubular dysfunction and defective glucose and galactose utilization (81).

\section{GSD12}

\section{Clinical}

GSD12 also known as ALDOA deficiency, results from impaired fructose-1,6-bisphosphate aldolase A activity, essential for interconversion of fructose-1,6-bisphosphate to glyceraldehyde 3-phosphate and dihydroxyacetone phosphate in glycolysis, with resultant hereditary nonspherocytic hemolytic anemia and myopathy (82).

In contrast, overexpression of aldolase A is associated with multiple forms of cancer including squamous cell carcinoma of the lung, hepatocellular, and renal cancer suggestive that increased glycolysis promotes tumor growth in cells (83).

\section{Metabolic findings and diagnosis}

Findings of hemolytic anemia, rhabdomyolysis and myoglobinuria can be confirmed with molecular analysis of $A L D O A$ gene. Red cells enzymatic assay can show decreased activity.

\section{Treatment}

No known specific except symptomatic and preventive management of myopathy and hemolytic anemia complications.

\section{Genetics and epidemiology}

GSD12 is a rare autosomal recessive disorder caused by mutations of $A L D O A$ gene on chromosome 16p11.2

\section{GSD13}

\section{Clinical}

GSD13, also known as Enolase-beta deficiency results from impaired beta-enolase activity, necessary for interconversion of 2-phosphoglycerate and phosphoenolpyruvate The skeletal muscle isozyme impairments presents with adultonset myalgia post exertion, with mildly elevated CK levels (84) to recurrent rhabdomyolysis (85).

\section{Metabolic findings and diagnosis}

Diagnostic confirmation requires molecular analysis of ENO3 gene.

\section{Treatment}

No specific treatment described yet.

\section{Genetics and epidemiology}

GSD13 is a rare autosomal recessive disorder caused by mutations of the ENO3 gene on chromosome 17p13.2.

\section{GSD14}

\section{Clinical}

GSD14, also known as phosphoglucomutase-1 deficiency or congenital disorder of glycosylation type It CDG-1T has wide clinical spectrum with predominantly milder myopathy form or severe form with multisystem involvement and congenital anomalies (86).

\section{Metabolic findings and diagnosis}

Diagnostic confirmation requires molecular analysis of the PGM1 gene.

\section{Treatment}

In a small study, supplementation with up to $1.5 \mathrm{~g} / \mathrm{kg} /$ day of oral D-galactose showed improvement or normalization of liver function, coagulation profile and transferrin profile (86).

\section{Genetics and epidemiology}

GSD14 is a rare autosomal recessive disorder caused by 
mutations of the PGM1 gene on chromosome 1p31.3 (87).

\section{GSD15}

\section{Clinical}

GSD15, also known as Glycogenin deficiency results from impaired glycosyltransferase necessary for short glucose polymer formation from UDP-glucose and glycogen formation, leading to depletion of glycogen in skeletal muscle and abnormal glycogen storage in the heart and resultant myopathy, cardiomyopathy and or arrhythmias (88).

\section{Metabolic findings and diagnosis}

Molecular analysis of GYG1 gene provides definitive diagnosis. Low skeletal muscle glycogen or abnormal cardiac muscle glycogen in the heart in patients with cardiomyopathy (88).

\section{Treatment}

No known treatment but glucose infusion during exercise showed improved exercise tolerance (89).

\section{Genetics and epidemiology}

GSD15 is a rare autosomal recessive disorder caused by mutations of GYG1 gene on chromosome 3q24.

\section{Other cardiac glycogenosis}

\section{Danon disease}

Diagnosed by mutations in LAMP2 gene located on chromosome Xq24, affecting lysosomal associated membrane protein-2 function of hydrolase sequestration and resultant lysosomal autolytic functions; leads to glycogen and autophagic materials accumulation in muscles and presents with cardiomyopathy, skeletal myopathy, intellectual disability, retinopathy or maculopathy in adolescent and younger adult males mostly, and milder presentation in hemizygous females (90-92).

\section{AMP activated protein kinase deficiency}

Is a cardiac phosphorylase kinase deficiency impairing fatty acid oxidation, glycolysis and glucose oxidation in response to energy demands leading to glycogen storage in cardiac muscles; secondary to mutations in PRKAG2 gene and has autosomal dominant inheritance. Presentations include lethal congenital or early childhood fatal (93) but can present in adolescence with Wolff-Parkinson-
White syndrome (WPW on EKG) with progressive fatal cardiomyopathy; requiring pacemaker or cardiac transplantation.

\section{Brain glycogenoses}

\section{Lafora disease}

Is a progressive myoclonic epilepsy with neurodegeneration in mid childhood to adolescent, caused by mutation in the EPM2 gene on chromosome 6q24.3, with autosomal recessive inheritance, leading to abnormal glycogen accumulation called Lafora bodies in neuronal axons and dendrites (94).

\section{Thoughts on future directions}

GSDs and glycogenosis defects, though, heterogenous and individually rare; predominantly affect liver, muscles, heart and in rare instance brain from infancy to adulthood. Heightened clinical suspicion can lead to GSD diagnosis in primary care and in-patient setting. Common laboratory biochemical evaluation or EKG with a timely referral to biochemical geneticist can help GSD diagnosis. Medical crises in most GSD are preventable with simple nutritional measures and prevention of energy deficiency triggers. Newborn Screening is changing the natural history of Pompe and lessons from ERT management still unfolding. In general, proactive symptomatic treatment and compliance using integrated behavior health model can help prevent co-morbidities such as intellectual disability, growth delay, organ failure or malignancy.

\section{Acknowledgements}

None.

\section{Footnote}

Conflicts of Interest: The authors have no conflicts of interest to declare.

\section{References}

1. Litwack G, Litwack G. Glycogen and Glycogenolysis. Human Biochemistry. Academic Press, 2018:161-81.

2. Roach PJ, Depaoli-roach AA, Hurley TD et al. Glycogen and its metabolism: some new developments and old themes. Biochem J 2012;441:763-87. 
3. Tarnopolsky MA. Metabolic Myopathies. Continuum (Minneap Minn) 2016;22:1829-51.

4. DiMauro S, Spiegel R. Progress and problems in muscle glycogenoses. Acta Myol 2011;30:96-102.

5. Aynsley-Green A, Williamson DH, Gitzelmann R. Hepatic glycogen synthetase deficiency. Definition of syndrome from metabolic and enzyme studies on a 9-yearold girl. Arch Dis Child 1977;52:573-9.

6. Gitzelmann R, Spycher MA, Feil G, et al. Liver glycogen synthase deficiency: a rarely diagnosed entity. Eur J Pediatr 1996;155:561-7.

7. Rutledge SL, Atchison J, Bosshard NU et al. Case report: liver glycogen synthase deficiency--a cause of ketotic hypoglycemia. Pediatrics. 2001;108:495-7.

8. Aynsley-Green A, Williamson DH, Gitzelmann R. The dietary treatment of hepatic glycogen synthetase deficiency. Helv Paediatr Acta 1977;32:71-5.

9. Aynsley-Green A, Williamson DH, Gitzelmann R. Asymptomatic hepatic glycogen-synthetase deficiency. Lancet 1978;1:147-8.

10. Chen Y'T, Kishnani PS, Koeberl D. Glycogen Storage Diseases. In: Beaudet AL, Vogelstein B, Kinzler KW, et al. editors. The Online Metabolic and Molecular Bases of Inherited Disease New York, NY: The McGraw-Hill Companies, Inc., 2014.

11. Heller S, Worona L, Consuelo A. Nutritional Therapy for Glycogen Storage Diseases. J Pediatr Gastroenterol Nutr 2008;47:S15-21.

12. Orho M, Bosshard NU, Buist NR, et al. Mutations in the liver glycogen synthase gene in children with hypoglycemia due to glycogen storage disease type 0. J Clin Invest 1998;102:507-15.

13. Kasapkara ÇS, Aycan Z, Açoğlu E, et al. Case Report The variable clinical phenotype of three patients with hepatic glycogen synthase deficiency. J Pediatr Endocrinol Metab 2017;30:459-62.

14. Smit GP. The long-term outcome of patients with glycogen storage disease type Ia. Eur J Pediatr 1993;152 Suppl 1:S52-5.

15. Bali DS, Chen YT, Austin S, et al. Glycogen Storage Disease Type I. GeneReviews®. Seattle: University of Washington, 1993.

16. Rake JP, Visser G, Labrune P, et al. Glycogen storage disease type I: diagnosis, management, clinical course and outcome. Results of the European Study on Glycogen Storage Disease Type I (ESGSD I). Eur J Pediatr 2002;161:S20-34.

17. Talente GM, Coleman RA, Alter C, et al. Glycogen storage disease in adults. Ann Intern Med 1994;120:218-26.

18. Wang DQ, Carreras CT, Kishnani PS, et al. Characterization and pathogenesis of anemia in glycogen storage disease type Ia and Ib. Genet Med 2012;14:795-9.

19. Sechi A, Deroma L, Lapolla A, et al. Fertility and pregnancy in women affected by glycogen storage disease type I, results of a multicenter Italian study. J Inherit Metab Dis 2013;36:83-9.

20. Kishnani PS, Austin SL, Bali DS, et al. Diagnosis and management of glycogen storage disease type I: a practice guideline of the American College of Medical Genetics and Genomics. Genet Med 2014;16:e1.

21. Trioche P, Francoual J, Capel L, et al. Apolipoprotein E polymorphism and serum concentrations in patients with glycogen storage disease type Ia. J Inherit Metab Dis 2000;23:107-12.

22. Chou JY, Jun HS, Mansfield BC. Type I glycogen storage diseases: disorders of the glucose-6-phosphatase/glucose6-phosphate transporter complexes. J Inherit Metab Dis 2015;38:511-9.

23. Qu Y, Abdenur JE, Desnick RJ, et al. Molecular Prenatal Diagnosis Of Glycogen Storage Disease TYPE Ia. Prenat Diagn 1996;16:333-6.

24. Bhattacharya K. Dietary dilemmas in the management of glycogen storage disease type I. J Inherit Metab Dis 2011;34:621-9.

25. Boers SJB, Visser G, Smit PGPA, et al. Liver transplantation in glycogen storage disease type I. Orphanet J Rare Dis 2014;9:47.

26. Chou JY, Jun HS, Mansfield BC. Glycogen storage disease type I and G6Pase- $\beta$ deficiency: etiology and therapy. Nat Rev Endocrinol 2010;6:676-88.

27. Gjorgjieva M, Monteillet L, Calderaro J, et al. Polycystic kidney features of the renal pathology in glycogen storage disease type I: possible evolution to renal neoplasia. J Inherit Metab Dis 2018. [Epub ahead of print].

28. Lei KJ, Shelly LL, Pan CJ, et al. Mutations in the glucose6-phosphatase gene that cause glycogen storage disease type 1a. Science 1993;262:580-3.

29. Ekstein J, Rubin BY, Weinstein DA, et al. Mutation frequencies for glycogen storage disease Ia in the Ashkenazi Jewish population. Am J Med Genet 2004;129A:162-4.

30. Visser G, de Jager W, Verhagen LP, et al. Survival, but not maturation, is affected in neutrophil progenitors from GSD-1b patients. J Inherit Metab Dis 2012;35:287-300.

31. Visser G, Rake J, Labrune P, et al. Granulocyte colonystimulating factor in glycogen storage disease type $1 \mathrm{~b}$. Results of the European Study on Glycogen Storage 
Disease Type 1. Eur J Pediatr 2002;161:S83-7.

32. Melis D, Pivonello R, Parenti G, et al. Increased Prevalence of Thyroid Autoimmunity and Hypothyroidism in Patients with Glycogen Storage Disease Type I. J Pediatr 2007;150:300-5, 305.e1

33. Hiraiwa H, Pan CJ, Lin B, et al. Inactivation of the glucose 6-phosphate transporter causes glycogen storage disease type 1b. J Biol Chem 1999;274:5532-6.

34. Ercan-Fang N, Gannon MC, Rath VL, et al. Integrated effects of multiple modulators on human liver glycogen phosphorylase a. Am J Physiol Endocrinol Metab 2002;283:E29-37.

35. Kishnani PS, Chen YT. Disorders of Glycogen Metabolism. In: Kline MW. editor. Rudolph's Pediatrics, 23e New York, NY: McGraw-Hill Education, 2018.

36. Chang S, Rosenberg MJ, Morton H, et al. Identification of a mutation in liver glycogen phosphorylase in glycogen storage disease type VI. Hum Mol Genet. 1998;7:865-70.

37. Burwinkel B, Bakker HD, Herschkovitz E, et al. Mutations in the liver glycogen phosphorylase gene (PYGL) underlying glycogenosis type VI. Am J Hum Genet 1998;62:785-91.

38. Schimke RN, Zakheim RM, Corder RC, et al. Glycogen storage disease type IX: benign glycogenosis of liver and hepatic phosphorylase kinase deficiency. J Pediatr 1973;83:1031-4.

39. Beauchamp NJ, Dalton A, Ramaswami U, et al. Glycogen storage disease type IX: High variability in clinical phenotype. Mol Genet Metab 2007;92:88-99.

40. Davidson JJ, Ozçelik T, Hamacher C, et al. cDNA cloning of a liver isoform of the phosphorylase kinase alpha subunit and mapping of the gene to Xp22.2-p22.1, the region of human X-linked liver glycogenosis. Proc Natl Acad Sci U S A 1992;89:2096-100.

41. Burwinkel B, Tanner MS, Kilimann MW. Phosphorylase kinase deficient liver glycogenosis: progression to cirrhosis in infancy associated with PHKG2 mutations (H144Y and L225R). J Med Genet 2000;37:376-7.

42. Burwinkel B, Shiomi S, Al Zaben A, et al. Liver glycogenosis due to phosphorylase kinase deficiency: PHKG2 gene structure and mutations associated with cirrhosis. Hum Mol Genet 1998;7:149-54.

43. Lucchiari S, Santoro D, Pagliarani S, et al. Clinical, biochemical and genetic features of glycogen debranching enzyme deficiency. Acta Myol 2007;26:72-4.

44. Sentner CP, Hoogeveen IJ, Weinstein DA, et al. Glycogen storage disease type III: diagnosis, genotype, management, clinical course and outcome. J Inherit Metab Dis
2016;39:697-704.

45. Wolfsdorf JI, Holm IA, Weinstein DA. Glycogen Storage Diseases: Phenotypic, Genetic, and Biochemical Characteristics, and Therapy. Endocrinol Metab Clin North Am 1999;28:801-23.

46. Kishnani PS, Austin SL, Arn P, et al. Glycogen Storage Disease Type III diagnosis and management guidelines. Genet Med 2010;12:446-63.

47. Mayorandan S, Meyer U, Das AM, et al. Glycogen storage disease type III: modified Atkins diet improves myopathy. Orphanet J Rare Dis 2014;9:196.

48. Bruno C, van Diggelen OP, Cassandrini D, et al. Clinical and genetic heterogeneity of branching enzyme deficiency (glycogenosis type IV). Neurology 2004;63:1053-8.

49. Burrow TA, Hopkin RJ, Bove KE, et al. Non-lethal congenital hypotonia due to glycogen storage disease type IV. Am J Med Genet Part A 2006;140:878-82.

50. Bruno C, Cassandrini D, Di Mauro S, et al. Neuromuscular forms of glycogen branching enzyme deficiency. Acta Myol 2007;26:75-8.

51. Szymańska E, Szymańska S, Truszkowska G, et al. Variable clinical presentation of glycogen storage disease type IV: from severe hepatosplenomegaly to cardiac insufficiency. Some discrepancies in genetic and biochemical abnormalities. Arch Med Sci 2018;14:237-47.

52. Greene HL, Brown BI, McClenathan DT, et al. A new variant of type IV glycogenosis: deficiency of branching enzyme activity without apparent progressive liver disease. Hepatology 1988;8:302-6.

53. McConkie-Rosell A, Wilson C, Kishnani P, et al. Clinical and laboratory findings in four patients with the nonprogressive hepatic form of type IV glycogen storage disease. J Inherit Metab Dis 1996;19:51-8.

54. Roscher A, Patel J, Hewson S, et al. The natural history of glycogen storage disease types VI and IX: Long-term outcome from the largest metabolic center in Canada. Mol Genet Metab 2014;113:171-6.

55. Kollberg G, Tulinius M, Gilljam T, et al. Cardiomyopathy and exercise intolerance in muscle glycogen storage disease 0. N Engl J Med 2007;357:1507-14.

56. Cameron JM, Levandovskiy V, MacKay N, et al. Identification of a novel mutation in GYS1 (muscle-specific glycogen synthase) resulting in sudden cardiac death, that is diagnosable from skin fibroblasts. Mol Genet Metab 2009;98:378-82.

57. Sukigara S, Liang WC, Komaki H, et al. Muscle glycogen storage disease 0 presenting recurrent syncope with weakness and myalgia. Neuromuscul Disord 
2012;22:162-5.

58. Lim JA, Li L, Raben N. Pompe disease: From pathophysiology to therapy and back again. Front Aging Neurosci 2014;6:177.

59. Slonim AE, Bulone L, Ritz S, et al. Identification of two subtypes of infantile acid maltase deficiency. J Pediatr 2000;137:283-5.

60. Güngör D, Reuser AJJ. How to describe the clinical spectrum in Pompe disease? Am J Med Genet Part A 2013;161A:399-400.

61. Amartino H, Painceira D, Pomponio R, et al. Two clinical forms of glycogen-storage disease type II in two generations of the same family. Clin Genet 2006;69:187-8.

62. Kishnani PS, Beckemeyer AA, Mendelsohn NJ. The new era of Pompe disease: Advances in the detection, understanding of the phenotypic spectrum, pathophysiology, and management. Am J Med Genet Part C Semin Med Genet 2012;160C:1-7.

63. Kroos M, Hoogeveen-Westerveld M, van der Ploeg A, et al. The genotype-phenotype correlation in Pompe disease. Am J Med Genet Part C Semin Med Genet 2012;160C:59-68.

64. Bembi B, Cerini E, Danesino C, et al. Diagnosis of glycogenosis type II. Neurology 2008;71:S4-11.

65. Chien YH, Hwu WL, Lee NC. Pompe disease: Early diagnosis and early treatment make a difference. Pediatr Neonatol 2013;54:219-27.

66. Bodamer OA, Scott CR, Giugliani R. Newborn Screening for Pompe Disease. Pediatrics 2017;140:S4-13.

67. Banugaria SG, Prater SN, Ng YK, et al. The impact of antibodies on clinical outcomes in diseases treated with therapeutic protein: Lessons learned from infantile Pompe disease. Genet Med 2011;13:729-36.

68. van der Ploeg AT, Clemens PR, Corzo D, et al. A Randomized Study of Alglucosidase Alfa in Late-Onset Pompe's Disease. N Engl J Med 2010;362:1396-406.

69. Haller RG, Wyrick P, Taivassalo T, et al. Aerobic conditioning: An effective therapy in McArdle's disease. Ann Neurol 2006;59:922-8.

70. Vissing J, Haller RG. The Effect of Oral Sucrose on Exercise Tolerance in Patients with McArdle's Disease. N Engl J Med 2003;349:2503-9.

71. Haller RG. Treatment of McArdle disease. Arch Neurol 2000;57:923-4.

72. Nakajima H, Raben N, Hamaguchi T, et al. Phosphofructokinase deficiency; past, present and future. Curr Mol Med 2002;2:197-212.

73. Toscano A, Musumeci O. Tarui disease and distal glycogenoses: Clinical and genetic update. Acta Myol 2007;26:105-7.

74. Preisler N, Orngreen MC, Echaniz-Laguna A, et al. Muscle phosphorylase kinase deficiency: a neutral metabolic variant or a disease? Neurology 2012;78:265-8.

75. Vissing J, Quistorff B, Haller RG. Effect of fuels on exercise capacity in muscle phosphoglycerate mutase deficiency. Arch Neurol 2005;62:1440-3.

76. Koo B, Oskarsson B. Phosphoglycerate mutase deficiency (glycogen storage disease $\mathrm{X}$ ) caused by a novel variant in PGAM-M. Neuromuscul Disord 2016;26:688-90.

77. Naini A, Toscano A, Musumeci O, et al. Muscle phosphoglycerate mutase deficiency revisited. Arch Neurol 2009;66:394-8.

78. OMIM Entry - \# 612933 - GLYCOGEN STORAGE DISEASE XI; GSD11 [cited 2018 Oct 9]. Available online: https://www.omim.org/entry/612933?search=gsd11\&highl ight=gsd 11

79. Anai T, Urata K, Tanaka Y, et al. Pregnancy complicated with lactate dehydrogenase $M$-subunit deficiency: the first case report. J Obstet Gynaecol Res 2002;28:108-11.

80. Wakabayashi H, Tsuchiya M, Yoshino K, et al. Hereditary deficiency of lactate dehydrogenase H-subunit. Intern Med 1996;35:550-4.

81. Santer R, Groth S, Kinner M, et al. The mutation spectrum of the facilitative glucose transporter gene SLC2A2 (GLUT2) in patients with Fanconi-Bickel syndrome. Hum Genet 2002;110:21-9.

82. Mamoune A, Bahuau M, Hamel Y, et al. A thermolabile aldolase A mutant causes fever-induced recurrent rhabdomyolysis without hemolytic anemia. Wilkie AOM, editor. PLoS Genet 2014;10:e1004711.

83. Du S, Guan Z, Hao L, et al. Fructose-bisphosphate aldolase $\mathrm{a}$ is a potential metastasis-associated marker of lung squamous cell carcinoma and promotes lung cell tumorigenesis and migration. PLoS One 2014;9:e85804.

84. Comi GP, Fortunato F, Lucchiari S, et al. Beta-enolase deficiency, a new metabolic myopathy of distal glycolysis. Ann Neurol 2001;50:202-7.

85. Musumeci O, Brady S, Rodolico C, et al. Recurrent rhabdomyolysis due to muscle $\beta$-enolase deficiency: very rare or underestimated? J Neurol 2014;261:2424-8.

86. Morava E, Wong S, Lefeber D. Disease severity and clinical outcome in phosphoglucomutase deficiency. J Inherit Metab Dis 2015;38:207-9.

87. Wong SY, Gadomski T, Kozicz T, et al. Defining the Phenotype and Assessing Severity in Phosphoglucomutase-1 Deficiency. J Pediatr 
2016;175:130-136.e8.

88. Hedberg-Oldfors C, Glamuzina E, Ruygrok P, et al. Cardiomyopathy as presenting sign of glycogenin-1 deficiency-report of three cases and review of the literature. J Inherit Metab Dis 2017;40:139-49.

89. Stemmerik MG, Madsen KL, Laforêt P, et al. Muscle glycogen synthesis and breakdown are both impaired in glycogenin-1 deficiency. Neurology 2017;89:2491-4.

90. Danon MJ, Oh SJ, DiMauro S, et al. Lysosomal glycogen storage disease with normal acid maltase. Neurology 1981;31:51-7.

91. Schorderet DF, Cottet S, Lobrinus JA, et al. Retinopathy in Danon Disease. Arch Ophthalmol 2007;125:231-6.

Cite this article as: Kanungo S, Wells K, Tribett T, ElGharbawy A. Glycogen metabolism and glycogen storage disorders. Ann Transl Med 2018;6(24):474. doi: 10.21037/ atm.2018.10.59
92. Majer F, Piherova L, Reboun M, et al. LAMP2 exon-copy number variations in Danon disease heterozygote female probands: Infrequent or underdetected? Am J Med Genet Part A 2018;176:2430-4.

93. Burwinkel B, Scott JW, Bührer C, et al. Fatal congenital heart glycogenosis caused by a recurrent activating $\mathrm{R} 531 \mathrm{Q}$ mutation in the gamma 2-subunit of AMP-activated protein kinase (PRKAG2), not by phosphorylase kinase deficiency. Am J Hum Genet 2005;76:1034-49.

94. Ramachandran N, Girard JM, Turnbull J, et al. The autosomal recessively inherited progressive myoclonus epilepsies and their genes. Epilepsia 2009;50:29-36. 